
8 Research Square
Preprints are preliminary reports that have not undergone peer review.
They should not be considered conclusive, used to inform clinical practice,
or referenced by the media as validated information.

\title{
The Advanced Performance of Microbial Consortium for Simultaneous Utilization of Glucose and Xylose to Produce Lactic Acid Directly from Dilute Sulfuric Acid Pretreated Corn Stover
}

\author{
Yaqin Sun ( $\nabla$ sunyaqin@dlut.edu.cn ) \\ Dalian University of Technology \\ Xiaoying Li \\ Dalian University of Technology \\ Lida Wu \\ Jilin COFCO Biochemistry Co. Ltd. \\ Yi Li \\ Jilin COFCO Biochemistry Co., Ltd. \\ Fan Li \\ Jilin COFCO Biochemistry Co., Ltd. \\ Zhilong Xiu \\ Dalian University of Technology \\ Yi Tong \\ Jilin COFCO Biochemistry Co., Ltd.
}

Research

Keywords: Lactic acid, Microbial consortium, Corn stover, Simultaneous saccharification and co-fermentation (SSCF), Non-detoxification

Posted Date: August 10th, 2021

DOI: https://doi.org/10.21203/rs.3.rs-778235/v1

License: (c) (i) This work is licensed under a Creative Commons Attribution 4.0 International License. Read Full License

Version of Record: A version of this preprint was published at Biotechnology for Biofuels on December 1st, 2021. See the published version at https://doi.org/10.1186/s13068-021-02085-8. 


\section{Abstract}

Background: Lignocellulosic feedstocks have attracted much attention as an alternative carbon source for lactic acid (LA) production with the advantages of ready availability, sustainability, and renewability. However, the production of LA from lignocellulose faces at least two major technical obstacles. The inhibitors derived from pretreatment of lignocellulose inhibit the growth of microorganism used in downstream hydrolysis and fermentation processes. In addition, most LA producers cannot to ferment pentose sugars and have carbon catabolite repression (CCR) effect. Microbial consortium with great robustness can use complex feedstocks displaying high bioconversion efficiency and has received great attention nowadays.

Results: in this study, a thermophilic LA producing consortium DUT50 was enriched and employed to enhance the utilization of corn stover (CS). Enterococcus was the dominant family, accounting for $93.66 \%$ abundance in DUT50, and the abundance of Lactobacillus, Bacillus, Lactococcus and Trichococcus, accounted for $2.68 \%$ in total. This consortium was highly resistant to inhibitors up to $10.90 \mathrm{~g} / \mathrm{L}$ derived from pretreatment of CS, metabolized hexose and pentose simultaneously without CCR effect. Based on consortium promising features, an efficient process of simultaneous saccharification and cofermentation (SSCF) was developed to produce LA from acid-pretreated corn stover. The economical route avoided the operations of solid-liquid separation and detoxification. The key influential factors, including dry biomass and cellulase loading, corn steep liquor powder concentration, and the pre-hydrolysis time were investigated and optimized. The highest LA titer of $71.04 \mathrm{~g} / \mathrm{L}$ with a yield of $0.49 \mathrm{~g} / \mathrm{g}-\mathrm{CS}$ was achieved at a dry biomass loading of $20 \%$ (w/v). This is the reported highest LA production from non-detoxified acid-pretreated corn stover via the SSCF process without wastewater generation. The interaction mode of Enterococcus was collaboration while the low abundance of Lactobacillus and Bacillus might metabolize xylose efficiently via the pentose phosphate pathway.

Conclusions: Our results demonstrated the potential advantage of symbiosis and provided a feasible and economical route to produce LA from lignocellulosic biomass in industrial scale.

\section{Background}

Lactic acid (LA), an important chemical, has versatile applications in the food, pharmaceutical, and chemical industries, especially as a monomer of biodegradable and biocompatible polylactic acid [1, 2]. Low-cost lignocellulosic feedstocks have attracted much attention as an alternative carbon source for LA production with the advantages of ready availability, sustainability, and renewability $[3,4]$. However, the production of LA from lignocellulose faces at least two major technical obstacles. Pretreatment of lignocellulosic biomass was one of the obstacles that hindered lignocelluloses utilization due to its recalcitrant nature [5]. During the pretreatment of lignocellulose, the formation of organic acid and furan derivatives could inhibit microbial growth and subsequent fermentation [6, 7]. In addition, hydrolysis of lignocellulose obtains a mixture of hexose and pentose sugars. However, most LA producers cannot to ferment pentose sugars and have carbon catabolite repression (CCR) effect [8].

Many studies have evaluated lignocellulosic biomass degradation and LA production by using physical, chemical and biological pretreatments. Among these methods of pretreatments, dilute acid pretreatment was used to efficiently produce lactic acid $[7,9,10]$. A high LA titer of $101.9 \mathrm{~g} / \mathrm{L}$ was obtained from sulfuric acid-pretreated and biodetoxified corn stover (CS). The poor yield of a mere $0.38 \mathrm{~g} / \mathrm{g}$ stover was due to $P$. acidilactici DQ2 cannot utilize xylose. Although $P$. acidilactici DQ2 showed tolerance to lignocellulose derived inhibitors, bio-detoxification procedure using fungus of $A$. resinae ZN1 was applied to pretreated CS for 5 days until $90 \%$ of furfural and hydroxylmethylfurfural (HMF) were removed. Engineered Pediococcus acidilactici TY112 with /dh gene disruption was also reported to produce L-LA from dilute acid pretreated and biodetoxified corn stover feedstock [9]. A LA titer of $76.76 \mathrm{~g} / \mathrm{L}$ was achieved at $25 \%$ (w/w) solids content. An efficient process from sulfuric acid pretreated wheat straw without operation of solid-liquid separation and detoxification was achieved by $B$. coagulans IPE22 [6]. As a result, $38.73 \mathrm{~g} / \mathrm{L}$ LA with a yield of $0.46 \mathrm{~g} / \mathrm{g}$-WS was obtained. However, the obtained titer could not be competed with commercial LA production. The results indicated lactic acid titer, yield and productivity using lignocellulose as feedstock highly depend on the level of inhibitors derived from lignocellulose and utilization efficiency of pentose.

Based on reported studies, the effective dilute acid pretreatment increases cellulose availability by solubilizing hemicellulose into pentose sugars and makes lactic acid production efficiently. However, the lignocellulose derived inhibitors significantly have an impact on LA production. Following pretreatment, the water washing for $\mathrm{pH}$ adjustment or complex detoxification procedures could remove the above-mentioned inhibitory compounds, but this process will inevitably lead to hemicellulose loss, generate a large amount of industrial wastewater and increase the environmental burden [3, 7,11$]$. Besides, low efficiency of pentose utilization and CCR effect cause a low productivity of LA, make LA production from lignocellulosic feedstocks less sustainable and competitive in cost. Therefore, the remarkable capabilities for strains to co-ferment pentose/ hexose efficiently and have resistence to inhibitors were desirable and preferred.

Currently, almost all commercial lactic acid production is based on carbohydrate fermentations using pure cultures of lactic acid bacteria [12]. Compared to pure culture fermentations, microbial consortium shows great robustness against environmental disturbances and microbial invasion. Especially, microbial consortium can use renewable and complex feedstocks displaying a higher bioconversion efficiency than pure culture, requiring less expensive purification processes [13]. Recently, microbial consortium is applied to LA production from un-pretreated sugarcane molasses [14] and hydrolysate of corn stover [15, 16]. The results indicated that microbial consortium could overcome the bottleneck of high metabolic burden and inhibition of the toxic byproducts derived from the biomass pretreated process. However, the effect of inhibitors on microbial consortium and the bioconversion process, the interaction mechanism of microbial consortium were still seldom investigated and unclear.

In this study, the objective of this study was to evaluate the feasibility of lactic acid production from acid-pretreated corn stover (pre-CS) without detoxification via simultaneous saccharification and co-fermentation (SSCF) by thermophilic microbial consortium. The robust microbial consortium showing high thermotolerance up to $50^{\circ} \mathrm{C}$ was enriched and adapted via the strategy of adaptive evolution engineering. To be highlighted, A feasible and economical route without solid-liquid separation and detoxification was studied with aiming to reduce wastewater generation as well as improve LA production by microbial consortium. The effect of total inhibitors derived from acid-pretreatment on microbial consortium DUT50 was evaluated. In addition, the key influential factors

Page 2/12 
such as cellulase loading, dry biomass loading, corn steep liquor powder (CSLP) loading, and the pre-hydrolysis time for the SSCF process were optimized. Finally, the interaction mechanism of microbial consortium DUT50 was investigated through serial dilution and construction of the synthetic microbial consortium.

\section{Results And Discussion}

\section{Sugars and inhibitors liberated during pretreatment of $\mathrm{CS}$ by dilute $\mathrm{H}_{2} \mathrm{SO}_{4}$}

The untreated corn stover (\% w/w, on a dry basis) contained mainly cellulose (31.18 \pm 0.23$)$, hemicellulose (26.95 \pm 0.14$)$, and lignin (16.43 \pm 0.27$)$. The CS used in this study contained a lower amount of cellulose, while amounts of hemicellulose and lignin were comparable to those of reported works [5, 10]. It was likely that differences in the components of CS might be due to its trait variations and growing lands. In this study, $\mathrm{CS}$ was firstly pretreated by dilute $\mathrm{H}_{2} \mathrm{SO}_{4}$ solution, and reducing sugars were release as well as the inhibitors. The effects of different CS loading via diluted- $\mathrm{H}_{2} \mathrm{SO}_{4} \mathrm{pretreatment}$ on sugars and inhibitory conversion were determined. Table 1 shows concentrations of liberated sugars and inhibitors in the hydrolysate liquors from various CS loading. Xylose was presented as the major sugar produced in the hydrolysate liquors followed by glucose and arabinose. A high xylose concentration of $45.22 \mathrm{~g} / \mathrm{L}$ with glucose concentration of $8.30 \mathrm{~g} / \mathrm{L}$ and arabinose concentration of $6.07 \mathrm{~g} / \mathrm{L}$ was obtained at a dry biomass loading of $35 \%$ (w/v). This may be due to hemicellulose has a lower molecular weight and is less lignified and highly amorphous compared to cellulose, thus it is easily hydrolyzed by acids [17]. The percentages of hemicellulose saccharification and cellulose saccharification decreased as the increase of corn stover loading during diluted acid pretreatment. The generated inhibitors including organic acid (acetic acid and citric acid), and furan derivatives (furfural, 5-hydroxymethyl furfural and vanillin) obviously increased with increasing of CS loading. The total inhibitors increased from $5.56 \mathrm{~g} / \mathrm{L}$ to $14.20 \mathrm{~g} / \mathrm{L}$ when the dry biomass loading range from $5 \%(\mathrm{w} / \mathrm{v})$ to $35 \%(\mathrm{w} / \mathrm{v})$. The rice straw pretreated with $\mathrm{H}_{3} \mathrm{PO}_{4}$ showed significantly lower total inhibitors when compared to those of the pretreatments with $\mathrm{H}_{2} \mathrm{SO}_{4}$ and $\mathrm{HCl}$ [17]. The total inhibitors of $5.10 \mathrm{~g} / \mathrm{L}$ were obtained when $1 \mathrm{~N} \mathrm{H}_{2} \mathrm{SO}_{4}$ pretreated rice straw with a dry biomass loading of $10 \%$ (w/v) for 60 min. As Table 1 shown, the total inhibitors of $7.34 \mathrm{~g} / \mathrm{L}$ were obtained when $1 \%\left(\mathrm{v} / \mathrm{v}\right.$ ) $\mathrm{H}_{2} \mathrm{SO}_{4}$ pretreated CS with a dry biomass loading of $10 \%$ (w/v) for 120 min. The content of lignin of CS $(16.43 \%, w / w)$ in this study and lignin of rice straw $(15.10 \%, w / w)$ was similar. It may also suggest that pretreatment by a weak acid with a longer reaction time is preferred to obtain more undesirable byproducts.

Table 1

Microbial community analysis of the adaptive consortia and the diluted consortia of DUT50

\begin{tabular}{|c|c|c|c|c|c|c|c|}
\hline \multirow[t]{4}{*}{ Taxonomy } & \multicolumn{7}{|l|}{ Percentage (\%) } \\
\hline & DUT42 & DUT45 & DUT47 & \multirow{3}{*}{$\begin{array}{l}\text { DUT50 } \\
\left(50^{\circ} \mathrm{C}\right) \\
{ }^{*} \text { SRR14149088 }\end{array}$} & \multicolumn{3}{|c|}{ Diluted consortia of DUT50 } \\
\hline & $\left(42^{\circ} \mathrm{C}\right)$ & $\left(45^{\circ} \mathrm{C}\right)$ & $\left(47^{\circ} \mathrm{C}\right)$ & & \multirow{2}{*}{$\begin{array}{l}\times 10^{-2} \\
* \text { SRR14149131 }\end{array}$} & \multirow{2}{*}{$\begin{array}{l}\times 10^{-4} \\
* \text { *SRR14149130 }\end{array}$} & \multirow{2}{*}{$\begin{array}{l}\times 10^{-6} \\
* \text { SRR14149129 }\end{array}$} \\
\hline & *SRR14149087 & *SRR14149086 & *SRR14149085 & & & & \\
\hline Escherichia_Shigella & 95.30 & 82.80 & 0.04 & - & - & - & - \\
\hline Enterococcus & 4.18 & 16.43 & 90.82 & 93.66 & 99.27 & 99.53 & 98.89 \\
\hline Lactobacillus & 0.08 & 0.12 & 0.60 & 1.05 & - & - & - \\
\hline Bacillus & 0.05 & 0.04 & 0.18 & 0.87 & - & - & - \\
\hline Lactococcus & - & - & - & 0.38 & - & - & - \\
\hline Trichococcus & & & & 0.38 & - & - & - \\
\hline Burkholderia & 0.002 & - & 0.04 & - & 0.22 & 0.13 & 0.42 \\
\hline Streptophyta & & & & 0.02 & 0.02 & 0.01 & 0.02 \\
\hline Unclassified & 0.12 & 0.30 & 3.33 & 3.48 & 0.35 & 0.19 & 0.29 \\
\hline
\end{tabular}

*The accession number of microbial consortia in NCBI Sequence Read Archive

\section{Adaptive evolution of microbial consortia to high temperature and inhibitors}

To ensure an efficient lactic acid production from the agricultural waste substrate, a robust microbial consortium is highly required, regarding both a broad range of substrate utilization capability and resistance to different inhibitors or stressful conditions. In this study, a microbial consortium was enriched and adapted to high concentration of inhibitors $(7.34 \mathrm{~g} / \mathrm{L})$ derived from acid-pretreatment of CS and gradually increasing temperature. After long-term domestication with non-detoxified hydrolysate liquor in pre-CS, the stable functional microbial consortium with heat-resistant and inhibitor-tolerant capacities was achieved. 16S rRNA gene amplicon high-throughput sequencing was performed to investigate the bacterial composition of microbial consortium DUT50 during the evolution process. The result is presented in Table 2. Escherichia-Shigella was the predominant families at cultivation temperatures of $42{ }^{\circ} \mathrm{C}$ and 45 ${ }^{\circ} \mathrm{C}$, accounting for $95.30 \%$ and $82.80 \%$, respectively. Enterococcus occupied less proportion under the same condition, only $4.18 \%$ abundance was detected at cultivation a temperature of $42^{\circ} \mathrm{C}$. With the increasing of cultivation temperature, Enterococcus became the dominant family at $47^{\circ} \mathrm{C}$ and $50{ }^{\circ} \mathrm{C}$, accounting for $90.82 \%$ and $93.66 \%$, respectively. Escherichia-Shigella wasn't detected in microbial consortium at $50{ }^{\circ} \mathrm{C}$. The abundance analysis indicated that the genus of Enterococcus has greater resistance to high temperature than the genus of Escherichia_Shigella at the same inhibitors level. Moreover, the abundance of Lactobacillus, Bacillus, Lactococcus and Trichococcus, accounting for $2.68 \%$ in total, increased at $50{ }^{\circ} \mathrm{C}$. Especially, Lactococcus and Trichococcus didn't exist 
in microbial consortium when cultivation temperature was lower than $47^{\circ} \mathrm{C}$. This performance suggested that Lactococcus and Trichococcus might show an excellent heat-resistant capacity.

Table 2

The components of $\mathrm{H}_{2} \mathrm{SO}_{4}$-pretreated $\mathrm{CS}$ hydrolysate liquors with various dry biomass loading

\begin{tabular}{|c|c|c|c|c|c|c|c|c|c|}
\hline \multirow{2}{*}{$\begin{array}{l}\text { Dry loading (\%, } \\
\text { w/v) }\end{array}$} & \multicolumn{3}{|c|}{ Sugar concentration $(g / L)$} & \multicolumn{6}{|c|}{ Inhibitors concentration $(\mathrm{g} / \mathrm{L})$} \\
\hline & Glucose & Xylose & Arabinose & Citric acid & $\begin{array}{l}\text { Acetic } \\
\text { acid }\end{array}$ & Furfural & 5-HMF & Vanillin & Total \\
\hline 5 & $\begin{array}{l}1.13 \pm \\
0.10\end{array}$ & $8.44 \pm 0.04$ & $\begin{array}{l}1.22 \pm \\
0.02\end{array}$ & $\begin{array}{l}0.19 \pm \\
0.01\end{array}$ & $\begin{array}{l}0.93 \pm \\
0.03\end{array}$ & $\begin{array}{l}1.46 \pm \\
0.01\end{array}$ & $\begin{array}{l}1.35 \pm \\
0.01\end{array}$ & $\begin{array}{l}1.63 \pm \\
0.01\end{array}$ & $5.56 \pm 0.01$ \\
\hline 10 & $\begin{array}{l}3.49 \pm \\
0.10\end{array}$ & $\begin{array}{l}17.59 \pm \\
0.08\end{array}$ & $\begin{array}{l}1.35 \pm \\
0.04\end{array}$ & $\begin{array}{l}0.35 \pm \\
0.01\end{array}$ & $\begin{array}{l}1.75 \pm \\
0.01\end{array}$ & $\begin{array}{l}1.82 \pm \\
0.02\end{array}$ & $\begin{array}{l}1.49 \pm \\
0.02\end{array}$ & $\begin{array}{l}1.93 \pm \\
0.03\end{array}$ & $7.34 \pm 0.02$ \\
\hline 15 & $\begin{array}{l}4.12 \pm \\
0.30\end{array}$ & $\begin{array}{l}23.64 \pm \\
0.78\end{array}$ & $\begin{array}{l}4.32 \pm \\
0.85\end{array}$ & $\begin{array}{l}0.84 \pm \\
0.03\end{array}$ & $\begin{array}{l}2.51 \pm \\
0.01\end{array}$ & $\begin{array}{l}2.18 \pm \\
0.02\end{array}$ & $\begin{array}{l}1.93 \pm \\
0.01\end{array}$ & $\begin{array}{l}2.00 \pm \\
0.03\end{array}$ & $9.46 \pm 0.02$ \\
\hline 20 & $\begin{array}{l}6.14 \pm \\
0.42\end{array}$ & $\begin{array}{l}29.17 \pm \\
0.77\end{array}$ & $\begin{array}{l}3.28 \pm \\
0.42\end{array}$ & $\begin{array}{l}1.16 \pm \\
0.01\end{array}$ & $\begin{array}{l}2.88 \pm \\
0.04\end{array}$ & $\begin{array}{l}2.46 \pm \\
0.14\end{array}$ & $\begin{array}{l}2.20 \pm \\
0.08\end{array}$ & $\begin{array}{l}2.20 \pm \\
0.05\end{array}$ & $10.90 \pm 0.02$ \\
\hline 25 & $\begin{array}{l}6.80 \pm \\
0.18\end{array}$ & $\begin{array}{l}33.97 \pm \\
0.96\end{array}$ & $\begin{array}{l}4.44 \pm \\
0.22\end{array}$ & $\begin{array}{l}1.28 \pm \\
0.01\end{array}$ & $\begin{array}{l}3.24 \pm \\
0.37\end{array}$ & $\begin{array}{l}2.92 \pm \\
0.06\end{array}$ & $\begin{array}{l}2.45 \pm \\
0.05\end{array}$ & $\begin{array}{l}2.24 \pm \\
0.01\end{array}$ & $12.13 \pm 0.03$ \\
\hline 30 & $\begin{array}{l}7.71 \pm \\
0.13\end{array}$ & $\begin{array}{l}38.69 \pm \\
0.07\end{array}$ & $\begin{array}{l}5.50 \pm \\
0.08\end{array}$ & $\begin{array}{l}1.36 \pm \\
0.05\end{array}$ & $\begin{array}{l}4.28 \pm \\
0.05\end{array}$ & $\begin{array}{l}2.96 \pm \\
0.03\end{array}$ & $\begin{array}{l}2.82 \pm \\
0.05\end{array}$ & $\begin{array}{l}2.25 \pm \\
0.02\end{array}$ & $13.67 \pm 0.01$ \\
\hline 35 & $\begin{array}{l}8.30 \pm \\
0.43\end{array}$ & $\begin{array}{l}45.22 \pm \\
0.02\end{array}$ & $\begin{array}{l}6.07 \pm \\
0.38\end{array}$ & $\begin{array}{l}1.61 \pm \\
0.05\end{array}$ & $\begin{array}{l}4.43 \pm \\
0.60\end{array}$ & $\begin{array}{l}2.98 \pm \\
0.03\end{array}$ & $\begin{array}{l}2.97 \pm \\
0.01\end{array}$ & $\begin{array}{l}2.28 \pm \\
0.01\end{array}$ & $14.20 \pm 0.02$ \\
\hline
\end{tabular}

This unique thermophilic and inhibitor-tolerant properties of microbial consortium DUT50 may benefit the SSCF process of acid-pretreated CS without the operation of solid-liquid separation and detoxification, which matches the optimal cellulase activity, reduce microbial contamination risks, and has a high tolerance to inhibitors derived from the pretreatment process.

\section{Lactic acid production directly from pretreated corn stover by microbial consortium Fermentation of hydrolysate liquor}

At the dry CS loading of $10 \%(\mathrm{w} / \mathrm{v})$, the total sugars and the total inhibitors in the hydrolysate liquor of pre-CS were approximately $22.24 \mathrm{~g} / \mathrm{L}$ and $7.34 \mathrm{~g} / \mathrm{L}$, respectively. The total inhibitors included $0.35 \mathrm{~g} / \mathrm{L}$ citric acid, $1.75 \mathrm{~g} / \mathrm{L}$ acetic acid, $1.82 \mathrm{~g} / \mathrm{L}$ furfural, $1.49 \mathrm{~g} / \mathrm{L} 5-\mathrm{HMF}$, and $1.93 \mathrm{~g} / \mathrm{L}$ vanillin. Microbial consortium DUT50 was able to grow and produce lactic acid from hydrolysate liquor at this level of total inhibitors (Fig. $1 \mathrm{~A}$ ). This may be due to the adaptive evolution engineering improving the inhibitors tolerance of microbial consortium DUT50. It is important that microbial consortium DUT50 could simultaneously utilize glucose, xylose and arabinose in the hydrolysate without carbon catabolite repression (CCR) effect. DUT50 was able to completely consume glucose, xylose and arabinose within $115 \mathrm{~h}$ at $7.34 \mathrm{~g} / \mathrm{L}$ of total inhibitors. In addition, lactic acid was produced as the sole product and no other organic acid was detected which indicated that microbial consortium DUT50 might mainly consist of homofermentative lactic acid producing strains. As a result, lactic acid concentration of $19.01 \mathrm{~g} / \mathrm{L}$ with a comparable yield to total reducing sugars of $0.96 \mathrm{~g} / \mathrm{g}$ was obtained from $100 \%$ ( $/ \mathrm{v}$ ) hydrolysate liquor.

In previous report, $2 \mathrm{~g} / \mathrm{L}$ acetic acid inhibited obviously the growth of Pichia stipites for ethanol production [18]. The growth and butyric acid production of $C$. tyrobutyricum were completely inhibited by $1.2 \mathrm{~g} / \mathrm{L}$ furfural and $2.4 \mathrm{~g} / \mathrm{L} \mathrm{HMF}$, respectively [19]. Pediococcus acidilactici DQ2 was reported that had an extraordinary tolerance to $3.0 \mathrm{~g} / \mathrm{L}$ furfural and $3.0 \mathrm{~g} / \mathrm{L} \mathrm{HMF} \mathrm{[7].} \mathrm{However,} \mathrm{P.} \mathrm{acidilactici} \mathrm{DQ2} \mathrm{was} \mathrm{relatively} \mathrm{sensitive} \mathrm{to} \mathrm{formic} \mathrm{acid} \mathrm{and} \mathrm{vanillin.} \mathrm{As} \mathrm{a} \mathrm{result,} 0.5$ $\mathrm{g} / \mathrm{L}$ formic acid and $0.2 \mathrm{~g} / \mathrm{L}$ vanillin will inhibit in both the cell growth and lactic acid fermentation performance. The $\mathrm{H}_{3} \mathrm{PO}_{4}$-pretreated hydrolysate possessed the minimum inhibitory concentration up to $1.84 \mathrm{~g} / \mathrm{L}$ was mentioned for $E$. coli AS1600a during the succinate production [17]. In their study, the detoxification by adjusting the hydrolysate to $\mathrm{pH} 9$ by $\mathrm{NH}_{4} \mathrm{OH}$ was adopted to lower the toxicity of inhibitors in the hydrolysate. B. coagulans IPE22 showed significant growth inhibition at $1.0 \mathrm{~g} / \mathrm{L}$ formate, $3.0 \mathrm{~g} / \mathrm{L}$ furfural and $2.0 \mathrm{~g} / \mathrm{L} \mathrm{5-HMF}$, respectively [6]. And IPE22 exerted excellent ability to resist acetate and vanillin.

CCR-negative strains were desirable for biochemicals production from mixed sugars derived from lignocellulosic biomass. Some strains such as $E$. coli [17] and $B$. coagulans [6] have been reported to utilize glucose, xylose and arabinose simultaneously without CCR. Engineered E. coli AS1600a offers cotransporting glucose and xylose with the same transporter in which the CCR regulation is relieved. Thus it may efficiently generate ATPs from glycolysis, and conserving them for xylose metabolism via the pentose phosphate pathway.

\section{SSCF of cellulose solid fraction}

Acid pretreatment could effectively dissolve hemicellulose and lignin. Approximately $40 \%(\mathrm{w} / \mathrm{w})$ of CS was hydrolyzed through pretreatment and $60 \%$ (w/w) residues were retained at a dry biomass loading of $10 \%(\mathrm{w} / \mathrm{v})$. For $60 \mathrm{~g} / \mathrm{L}$ pretreated CS solid fraction with a pre-hydrolysis time of $12 \mathrm{~h}$, the maximum of glucose and xylose were obtained (Fig. 1.B). Microbial consortium DUT50 simultaneously utilized Xylose and glucose were utilized simultaneously and completely consumed within $28 \mathrm{~h}$. At the end of the fermentation, a lactic acid concentration of $29.06 \mathrm{~g} / \mathrm{L}$, with a yield to solid of pre-CS of $0.56 \mathrm{~g} / \mathrm{g}$ was produced. It was observed that lactic acid productivity via the SSCF process at $60 \mathrm{~g} / \mathrm{L}$ pretreated CS solid fraction was higher than that of $100 \%$ ( $\mathrm{v} / \mathrm{v}$ ) hydrolysate fraction. This is the cause of toxicity of inhibitors in hydrolysate liquor and low utilization rate of xylose. Generally, the washing process was

Page $4 / 12$ 
applied to remove the inhibitors remained in solid fraction and adjust $\mathrm{pH}$ to neutral. As a matter of fact, the washing-based detoxification and neutralization process would inevitably generate considerable wastewater and increase operating cost. In this study, the operation of washing detoxification was omitted and the solid fraction was directly utilized to produce lactic acid. A comparable yield of $0.56 \mathrm{~g} / \mathrm{g}$ to solid was obtained and the obtained concentration was not competitive due to the low dry biomass loading.

\title{
SSCF of acid-pretreated corn stover
}

Actually, the utilization of both hemicellulose hydrolysate liquor and cellulose solid fraction derived from lignocellulosic biomass was suggested to preferably sustainable productions of biofuels and biochemicals with reducing waste liquid generation. Therefore, the SSCF of pretreated CS including hydrolysate liquor and solid for lactic acid production was investigated in this study. The effect of dry biomass loading from $10 \%$ (w/v) to $20 \%$ (w/v) and total inhibitors concentration from $7.34 \mathrm{~g} / \mathrm{L}$ to $10.90 \mathrm{~g} / \mathrm{L}$ on LA production were evaluated by microbial consortium DUT50. Figure 2 showed LA production via the SSCF process from non-detoxified acid-pretreated CS by microbial consortium DUT50 under different dry biomass loading. The similar sugars utilization and lactic acid production pattern was observed. Microbial consortium DUT50 was able to grow and produce lactic acid from non-detoxified hydrolysate of CS and had a significant tolerance to total inhibitors up to $10.90 \mathrm{~g} / \mathrm{L}$. The total inhibitors included $1.16 \mathrm{~g} / \mathrm{L}$ citric acid, $2.88 \mathrm{~g} / \mathrm{L}$ acetic acid, $2.46 \mathrm{~g} / \mathrm{L}$ furfural, $2.20 \mathrm{~g} / \mathrm{L} 5-$ $\mathrm{HMF}$ and $2.20 \mathrm{~g} / \mathrm{L}$ vanillin. The increased total inhibitors concentration hardly affected the consortia growth, as well as the consumption of xylose and glucose. This is the reported highest inhibitors concentration capable for the cell growth of LA production.

For most microorganisms, xylose and glucose usually could not be simultaneously metabolized and the xylose consumption started only when almost no glucose remained in the medium. In our study, it is also noticed that xylose and arabinose were simultaneously consumed with glucose without carbon catabolite repression (CCR). The average consumption rate of xylose in media containing the mixture of glucose, xylose and arabinose was $0.12 \mathrm{~g} /(\mathrm{L} . \mathrm{h})$ at the total inhibitors of $7.34 \mathrm{~g} / \mathrm{L}$. Xylose was slowly consumed by microbial consortium DUT50 in the presence of glucose. The reason might due to the expression of xylose catabolizing genes in DUT50 were less repressed by glucose than those in other bacteria [5]. Lactic acid concentration increased along with the dry biomass loading and total inhibitors. And the maximum lactic acid titer of $64.64 \mathrm{~g} / \mathrm{L}$ with a yield of $0.45 \mathrm{~g} / \mathrm{g}$-CS was produced at the dry biomass loading of $20 \%(\mathrm{w} / \mathrm{v})$ and total inhibitors of $10.90 \mathrm{~g} / \mathrm{L}$. LA yield to CS decreased when the total inhibitors and dry biomass loading increased. As a result, a yield of 0.50 $\mathrm{g} / \mathrm{g}$-CS was obtained at the dry biomass loading of $10 \%(\mathrm{w} / \mathrm{v})$ and total inhibitors of $7.34 \mathrm{~g} / \mathrm{L}$. This might contribute to the high efficiency of heat and mass transfers with the decreasing of dry biomass loading.

Microbial consortium not only has significant tolerance to inhibitors derived from pretreatment, but also can utilize glucose, xylose and arabinose simultaneously without CCR effect. The characterization of thermophilic microbial consortium DUT50 showed its potential application for bioconversion of lignocellulosic biomass to lactic acid.

\section{Optimization of SSCF process}

Various influential factors in the SSCF process with microbial consortium DUT50 were investigated to achieve economic LA production. The cellulase loading, CSLP concentration, and the pre-hydrolysis time were optimized in this study.

Cellulase loading was critical for the saccharification in the SSCF process. Especially, when non-detoxified pre-CS is used, the inhibitors in hydrolysate liquor have an impact on cellulose saccharification by cellulase. The effect of cellulase loading and derived inhibitors from lignocellulose pretreatment on hydrolysis of CS was shown in Fig. 3. The results showed that increasing cellulase loading resulted in higher total sugar concentration. Despite cellulase loading higher than $35 \mathrm{FPU} / \mathrm{g}-\mathrm{CS}$, no significant differences were observed for glucose, xylose and arabinose concentration in non-detoxified CS. Especially, when the dry biomass loading was higher than $25 \%(\mathrm{w} / \mathrm{v})$, the efficiency of enzymatic saccharification was decreased (Fig. 3E). It may be due to the fact that the excess of enzyme absorbed onto the surface of CS restricted the diffusion process through the cellulose structure. When inhibitors were removed by washing, higher total sugar concentration for the hydrolysis of solid fraction in pre-CS was obtained under the less cellulase loading (Fig. 3A). The inhibitors derived from the pretreatment of CS have adverse impact on saccharification by cellulase. The effect could be eliminated via the operation of washing, biodetoxification, sodium bisulfite addition, etc $[7,10,17]$. However, washing would generate a large quantity of waste water while biodetoxification need a long period. In addition, the hydrolyaste fraction of pre-CS was also wasted which decreased the utilization yield of the total corn stover.

CSLP is an important nutrient for LA production and was tested to improve LA productivity under the utilization of sugarcane molasses, starchy biomass and etc $[14,20,21]$. In this study, with the addition of 10-20 g/L CSLP, LA concentration increased gradually from 58.28 to $66.11 \mathrm{~g} / \mathrm{L}$, while $65.33 \mathrm{~g} / \mathrm{L} \mathrm{LA}$ was obtained with $25 \mathrm{~g} / \mathrm{L} \mathrm{CSLP}$ (Fig. 4). With the increase of CSLP addition, the consumption rate of glucose and xylose increased. And as a result, the maximum productivity was obtained with $25 \mathrm{~g} / \mathrm{L}$ CSLP. Considering the economics of the SSCF process, $20 \mathrm{~g} / \mathrm{L}$ CSLP was regarded as the appropriate addition of nitrogen source.

Pre-hydrolysis time was then investigated in the SSCF process by microbial consortium DUT50 (Fig. 5). As the increase of pre-hydrolysis time from 0 to $6 \mathrm{~h}$, the initial reducing sugars including glucose, xylose, and arabinose were increased from $37.15 \mathrm{~g} / \mathrm{L}$ to $45.46 \mathrm{~g} / \mathrm{L}$. The highest glucose concentration of 30.86 $\mathrm{g} / \mathrm{L}, 37.50 \mathrm{~g} / \mathrm{L}, 37.82 \mathrm{~g} / \mathrm{L}$, and $36.15 \mathrm{~g} / \mathrm{L}$ were attained at $72 \mathrm{~h}, 72 \mathrm{~h}, 72 \mathrm{~h}, 60 \mathrm{~h}$ when the pre-hydrolysis time was $0 \mathrm{~h}, 2 \mathrm{~h}, 4 \mathrm{~h}, 6 \mathrm{~h}$, respectively. The highest LA concentration of $71.04 \mathrm{~g} / \mathrm{L}$ was achieved using $4 \mathrm{~h}$ pre-hydrolysis of pretreated CS.

The above results guided for the feasibility of pre-CS utilization without detoxification in LA production by thermophilic microbial consortium DUT50. And the optimum conditions for the SSCF process of pre-CS without the operations of solid-liquor separation and detoxification are determined to be $20 \%$ ( $\mathrm{w} / \mathrm{v}$ ) dry biomass loading, $35 \mathrm{FPU} / \mathrm{g}$-CS cellulase, $20 \mathrm{~g} / \mathrm{L} \mathrm{CSLP}$ and $4 \mathrm{~h}$ of pre-hydrolysis time. As a result, $71.04 \mathrm{~g} / \mathrm{L} \mathrm{LA}$ with a yield of $0.49 \mathrm{~g} / \mathrm{g}$-CS and a purity of L-LA of $96.8 \%$ were abtained. This is the reported highest lactic acid production from non-detoxified acid-pretreated corn stover via the SSCF process without wastewater generation.

\section{The mechanism of microbial consortium for advanced performance}

\author{
Page 5/12
}


Serial dilution is an easy and efficient way to isolate the microbial consortium with the simplest community structure and target function without isolating pure strains $[22,23]$. Therefore, in this study, serial dilution of original microbial consortium DUT50 in sterile saline was carried out and the performance of diluted consortia was evaluated as Fig. 6 shown. With the increasing dilution from $10^{-2}$ to $10^{-8}$, the performance of diluted microbial consortia decreased. The mini consortia consumed xylose slowly compared to the original microbial consortium DUT50. Bacterial community analysis showed that the genus of Lactobacillus, Bacillus, Lactococcus, and Trichococcus was eliminated after $10^{-2}$ dilution while the abundance of Enterococcus increased over $98.50 \%$. The results may be due to the fact that these four genera might utilize xylose efficiently. To verify this hypothesis, two strains of E. faecium DUT-S1 and DUT-S2 were isolated to utilize non-detoxified pre-CS to produce lactic acid, respectively. Xylose consumption rate was also both decreased, and 6.15 and $7.84 \mathrm{~g} / \mathrm{L}$ xylose was still remained for DUT-S1 and S2 in medium after $522 \mathrm{~h}$ which led to low lactic acid concentration and productivity, respectively.

In addition, the synthetic consortium of E. faecium DUT-S1 and DUT-S2 were constructed to improve the utilization of non-detoxified acid-pretreated CS. The consumption rate of xylose was also observed to decrease in the synthetic microbial consortium. There was still about $7.01 \mathrm{~g} / \mathrm{L}$ xylose remained in fermentation medium after $522 \mathrm{~h}$ by the synthetic consortium. Finally, $53.03 \mathrm{~g} / \mathrm{L}$ lactic acid, with a yield of $0.36 \mathrm{~g} / \mathrm{g}$-CS was obtained by the synthetic consortium. The fermentation performance of the synthetic consortium prior to the single strain implied that the interaction mechanism of $E$. faecium DUT-S1 and DUT-S2 was collaboration for non-detoxified CS utilization. However, compared to DUT50, synthetic microbial consortium showed a lower lactic acid production and yield. Therefore, the low abundance of genus such as Lactobacillus, Bacillus, Lactococcus and Trichococcus strains might play an important role in xylose utilization and LA production for the utilization of non-detoxified pre-CS. Among these low abundance genus, thermophilic Bacillus and Lactobacillus strains have recently reported with homofermentative behaviors metabolizing glucose and xylose simultaneously [5, 6, 24]. Xylose could be homo-fermented to LA by B. coagulans. In addition, xylose was consumed by B. coagulans NBRC12714 with an average consumption rate of $1.35 \mathrm{~g} /$ (L.h) in the presence of glucose [5]. Lactobacillus pentosus FL0421 was reported to metabolize xylose via the phosphoketolase pathway at high xylose concentration and acetic acid was produced as byproduct [24]. The results presented in this study indicated that the enriched and adapted microbial consortium DUT50 consists of Enterococcus, Lactobacillus, Bacillus, Lactococcus and Trichococcus is highly functional. No other organic acid and ethanol was detected during the whole fermentation period which indicating that microbial consortium DUT50 mainly consists of homo-fermentative lactic acid bacteria and the pathway of xylose metabolism might be pentose phosphate pathway. In this study, a lactic acid titer of $71.04 \mathrm{~g} / \mathrm{L}$ was obtained, which was as about $37 \%$ and $34 \%$ higher than that by single cultures of E. faecium and synthetic microbial consortium consists of Enterococcus, respectively. This is the reported highest lactic acid production from non-detoxified pretreated CS via the SSCF process without wastewater generation.

\section{Conclusions}

A thermophilic microbial consortium for LA production was enriched via adaptive evolution engineering. The consortium was highly resistant to inhibitors up to $10.90 \mathrm{~g} / \mathrm{L}$ derived from pretreatment of CS, metabolized hexose and pentose simultaneously without CCR. An economical process only consisting of CS pretreatment by dilute acid and SSCF process was developed for LA production. A LA titer of $71.04 \mathrm{~g} / \mathrm{L}$ with a yield of $0.49 \mathrm{~g} / \mathrm{g}-\mathrm{CS}$ was achieved from $20 \%$ (w/v) dry CS loading. The interaction mode of Enterococcus in consortium was collaboration while low abundance of Lactobacillus and Bacillus might metabolize xylose efficiently via the pentose phosphate pathway.

\section{Materials And Methods \\ Raw materials, enzymes and medium}

Corn stover (CS) that contains $31.18 \mathrm{wt} \%$ of cellulose, $26.95 \mathrm{wt} \%$ of hemicellulose and $16.43 \mathrm{wt} \%$ of lignin, was harvested from a farmer in Shandong province of China. The commercial cellulase of Cellic ${ }^{\circledR} \mathrm{CTec} 2$ used was purchased from Novozymes (China). CSLP with a nitrogen content of $9 \%$ (w/v) was afforded by Yuancheng Biotechnology Company, Liaoning, China [14]. All other chemicals were of reagent grade and commercially available.

The toxic enrichment medium (TEM) and seed medium was as follows: $7.34 \mathrm{~g} / \mathrm{L}$ total inhibitors $(1.75 \mathrm{~g} / \mathrm{L}$ acetic acid, $0.35 \mathrm{~g} / \mathrm{L}$ citric acid, $1.82 \mathrm{~g} / \mathrm{L}$ furfural, $1.49 \mathrm{~g} / \mathrm{L} 5-\mathrm{HMF}$ and $1.93 \mathrm{~g} / \mathrm{L}$ vanillin), $35 \mathrm{~g} / \mathrm{L}$ glucose, $3 \mathrm{~g} / \mathrm{L}$ xylose, $16 \mathrm{~g} / \mathrm{L} \mathrm{CSLP}, 2 \mathrm{~g} / \mathrm{L}$ ammonium citrate, $2 \mathrm{~g} / \mathrm{L}$ sodium acetate, $2 \mathrm{~g} / \mathrm{L} \mathrm{K}{ }_{2} \mathrm{HPO}{ }_{4}, 0.20 \mathrm{~g} / \mathrm{L}$ $\mathrm{MgSO}_{4} \cdot 7 \mathrm{H}_{2} \mathrm{O}, 0.05 \mathrm{~g} / \mathrm{L} \mathrm{MnSO}_{4} \cdot \mathrm{H}_{2} \mathrm{O}$.

The fermentation medium is as follows: $10-20 \%$ (w/v) dry CS loading, $10-25 \mathrm{~g} / \mathrm{L} \mathrm{CSLP,} 2 \mathrm{~g} / \mathrm{L}$ ammonium citrate, $5 \mathrm{~g} / \mathrm{L}$ sodium acetate, $2 \mathrm{~g} / \mathrm{L} \mathrm{K} \mathrm{HPO}_{4}, 0.58$ $\mathrm{g} / \mathrm{L} \mathrm{MgSO}{ }_{4} \cdot 7 \mathrm{H}_{2} \mathrm{O}, 0.25 \mathrm{~g} / \mathrm{L} \mathrm{MnSO}{ }_{4} \cdot \mathrm{H}_{2} \mathrm{O}$.

\section{Dilute sulfuric acid pretreatment of CS and non-detoxified SSCF process}

CS was milled into particles with size $<2 \mathrm{~mm}$ and then was pretreated by $1 \%\left(\mathrm{v} / \mathrm{v}\right.$ ) dilute $\mathrm{H}_{2} \mathrm{SO}_{4}$ solution with dry biomass loading of $10-25 \%$ (w/v). The pretreatment was carried out in a tank at $121^{\circ} \mathrm{C}$ for $120 \mathrm{~min}$, followed by cooling to room temperature and pH adjustment to $5.5 \mathrm{using} \mathrm{KOH}$ [25].

After the pretreatment, the contents including hydrolysate liquor and residues were together used as the substrate to produce lactic acid via the SSCF process. The SSCF process was performed under a non-sterilized condition in a $1 \mathrm{~L}$ bioreactor filled with $0.5 \mathrm{~L}$ of fermentation medium at $50{ }^{\circ} \mathrm{C}$ with the agitation of $200 \mathrm{rpm}$ and inoculation size of $5 \%(\mathrm{v} / \mathrm{v})$. Cellulase of $35 \mathrm{FPU} / \mathrm{g}-\mathrm{CS}$ was added into the unsterile medium before the seed culture was inoculated. The pH was

maintained at 5.5 by using an automatic feed of $2 \mathrm{M} \mathrm{NaOH}$ solution. Samples were taken periodically to determine the concentration of products and reducing sugar.

\section{Adaptive evolution engineering of microbial consortium to temperature and inhibitors}


The adaptation protocol was established to select thermophilic and inhibitors-tolerant microbial consortia improving the utilization of non-detoxified pre-CS. First, cattle stomach content was prepared by adding $10 \mathrm{~g}$ fresh content into $15 \mathrm{~mL}$ saline solution, mixing for 3 min with a vortex. Then, cattle stomach content was inoculated with $5 \%$ incubation into a toxic enrichment medium by an adaptive strategy of increasing temperature $\left(42{ }^{\circ} \mathrm{C}, 45^{\circ} \mathrm{C}, 47^{\circ} \mathrm{C}, 50^{\circ} \mathrm{C}\right)$. After half of the reducing sugars were consumed, the culture was transferred to a fresh adaptation medium with a higher temperature for consecutive cultivation. The culture was cultivated for five times at the same temperature before exposure to the higher one. After long-term domestication of 20 generations with non-detoxified hydrolysate liquor of pre-CS, the stable thermophilic and inhibitors-tolerant microbial consortium DUT50 was achieved.

\section{The construction of mini consortia and isolation of single strain}

Mini consortia were constructed by serial dilution $\left(10^{-2}\right.$ to $\left.10^{-8}\right)$ of the original consortium DUT50 with sterile saline and then incubated in the seed medium. Once sugars were completely consumed, the enriched consortia were serially transferred to the fresh seed medium with $5 \%$ inoculation three times for steady microbial composition.

Single strain from consortium DUT50 was isolated and purified by streaking on solid medium. Among 12 strains, two strains that have perfect utilization of hydrolysate of CS were further investigated. BLAST analysis of the 16S rRNA gene sequence of the isolated two strains demonstrated $100 \%$ similarity to Enterococcus faecium CBA7134. Thus, these two strains were designated as E. faecium DUT-S1 and E. faecium DUT-S2. The 16S rRNA sequence of $E$. faecium DUT-S1 and DUT-S2 was deposited in GenBank database under accession numbers MW479185.

\section{Composition analysis of microbial consortium}

The bacterial community composition of microbial consortia was investigated by $16 \mathrm{~S}$ rRNA gene amplicon high-throughput sequencing provided by Sangon Biotech in Shanghai, China. 16S rRNA gene sequences of the consortia DUT50 during the process of adaptive evolution, and dilution consortia have been submitted to the NCBI Sequence Read Archive and the related accession numbers were shown in Table 2.

\section{Analytical methods}

Glucose, xylose, arabinose and organic acid were analyzed using HPLC equipped with an Aminex HPX-87H column with a column temperature of $65^{\circ} \mathrm{C}$. Sulfuric acid ( $5 \mathrm{mmol} / \mathrm{L}$ ) was the mobile phase with a flow rate of $0.6 \mathrm{~mL} / \mathrm{min}$. The major inhibitors (acetate, furfural, 5 -HMF and vanillin) in hydrolysate liquor of pre-CS were analyzed by a C18 column at $285 \mathrm{~nm}$ with a UV detector [16]. The optical purity of the L-lactic acid was determined by HPLC equipped with an Astec ${ }^{\circledR}$ CLC-L Chiral column (Sigma Aldrich, Co.) maintained at $25^{\circ} \mathrm{C}$ with a UV detector at $254 \mathrm{~nm}$ [20].

The lactic acid yield ( $\mathrm{Y}$ ) was calculated as total lactic acid produced dividing by the dry matter of CS, expressing in $\mathrm{g} / \mathrm{g}$. The lactic acid productivity was calculated as lactic acid produced dividing by the fermentation time, expressing in $\mathrm{g} /(\mathrm{L} . \mathrm{h})$.

\section{Abbreviations}

LA

lactic acid; CS:corn stover; CSLP:corn steep liquor power; SSCF:simultaneous saccharification and co-fermentation; CCR:carbon catabolite repression; PreCS:acid-pretreated corn stover; HMF:hydroxylmethylfurfural.

\section{Declarations}

\section{Ethical approval and consent to participate}

Not applicable.

\section{Consent for publication}

Not applicable.

\section{Availability of data and materials}

The datasets used and/or analyzed during the current study are available from the corresponding author on reasonable request.

\section{Competing interests}

The authors declare no competing interests.

\section{Funding}

This work was supported by the National Natural Science Foundation of China [grant number 22078043].

\section{Authors' contributions}

YQS performed the cultures, drafted this manuscript, designed the experiments and analyzed results. XYL carried out the experiments and analyzed results. LDW, YL and FL advised on the experiments design. ZLX revised the manuscript. YT advised on the experiments design and revised the manuscript. All authors read and approved the final manuscript. 


\section{References}

1. Abdel-Rahman MA, Sonomoto K. Opportunities to overcome the current limitations and challenges for efficient microbial production of optically pure lactic acid. J Biotechnol. 2016;236:176-92.

2. Ahmad A, Banat F, Taher H. A review on the lactic acid fermentation from low-cost renewable materials: Recent developments and challenges. Environ Technol Innovation. 2020;20:101138.

3. Yuan SF, Hsu TC, Wang CA, Jang MF, Kuo YC, Alper HS, Guo GL, Hwang WS. Production of optically pure I(+)-lactic acid from waste plywood chips using an isolated thermotolerant Enterococcus faecalis SI at a pilot scale. J Ind Microbiol Biotechnol. 2018;45(11):961-70.

4. Isikgor FH, Becer CR. Lignocellulosic biomass: a sustainable platform for the production of bio-based chemicals and polymers. Polym Chem. 2015;6(25):4497-559.

5. Ma KD, Hu GQ, Pan LW, Wang ZC, Zhou Y, Wang YW, Ruan ZY, He MX. Highly efficient production of optically pure L-lactic acid from corn stover hydrolysate by thermophilic Bacillus coagulans. Bioresour Technol. 2016;219:114-22.

6. Zhang YM, Chen XR, Luo JQ, Qi BK, Wan YH. An efficient process for lactic acid production from wheat straw by a newly isolated Bacillus coagulans strain IPE22. Bioresour Technol. 2014;158:396-9.

7. Zhao K, Qiao QG, Chu DQ, Gu HQ, Dao TH, Zhang J, Bao J. Simultaneous saccharification and high titer lactic acid fermentation of corn stover using a newly isolated lactic acid bacterium Pediococcus acidilactici DQ2. Bioresour Technol. 2013;135:481-9.

8. Abdel-Rahman MA, Tashiro Y, Sonomoto K. Recent advances in lactic acid production by microbial fermentation processes. Biotechnol Adv. 2013;31(6):877-902.

9. Yi X, Zhang P, Sun J, Tu Y, Gao Q, Zhang J, Bao J. Engineering wild-type robust Pediococcus acidilactici strain for high titer L-and D-lactic acid production from corn stover feedstock. J Biotechnol. 2016;217:112-21.

10. Zhang Z, Li Y, Zhang J, Peng N, Liang Y, Zhao S. High-titer lactic acid production by Pediococcus acidilactici PA204 from corn stover through fed-batch simultaneous saccharification and fermentation. Microorg. 2020;8(10):1491.

11. Ouyang J, Ma R, Zheng ZJ, Cal C, Zhang M, Jiang T. Open fermentative production of L-lactic acid by Bacillus sp strain NLO1 using lignocellulosic hydrolyzates as low-cost raw material. Bioresour Technol. 2013;135:475-80.

12. Kim DH, Lee MK, Hwang Y, Im WT, Yun YM, Park C, Kim MS. Microbial granulation for lactic acid production. Biotechnol Bioeng. 2016;113(1):101-11.

13. Ben Said S, Or D. Synthetic microbial ecology: engineering habitats for modular consortia. Front Microbiol. 2017;8:1125.

14. Sun YQ, Xu ZZ, Zheng YF, Zhou JJ, Xiu ZL. Efficient production of lactic acid from sugarcane molasses by a newly microbial consortium CEE-DL15. Process Biochem. 2019;81:132-8.

15. Zhang YX, Vadlani PV. Lactic acid production from biomass-derived sugars via co-fermentation of Lactobacillus brevis and Lactobacillus plantarum. J Biosci Bioeng. 2015;119(6):694-9.

16. Sun YQ, Li XY, Wei CX, Qi WB, Xiu ZL. An aptly industrialized bioprocess for lactic acid production from corn stover using thermotolerant microbial consortia. Bioprocess Biosyst Eng. 2021. doi:10.1007/s00449-021-02616-5.

17. Jampatesh S, Sawisit A, Wong N, Jantama SS, Jantama K. Evaluation of inhibitory effect and feasible utilization of dilute acid-pretreated rice straws on succinate production by metabolically engineered Escherichia coli AS1600a. Bioresour Technol. 2019;273:93-102.

18. Guo GL, Chen WH, Chen WH, Men LC, Hwang WS. Characterization of dilute acid pretreatment of silvergrass for ethanol production. Bioresour Technol. 2008;99(14):6046-53.

19. Liu Y, Geng YX, Zhou Q, Yuan WQ. The effect of furfural and 5-hydroxymethyl furfural on butyric acid fermentation by Clostridium tyrobutyricum. J Chem Technol Biotechnol. 2018;93(3):849-54.

20. Sun YQ, Yang Y, Liu HH, Wei CX, Qi WB, Xiu ZL. Simultaneous liquification, saccharification and fermentation of L-lactic acid using aging paddy rice with hull by an isolated high-thermotolerant Enterococcus faecalis DUT1805. Bioprocess Biosyst Eng. 2020; 43(9):1717-27.

21. Altaf $M$, Naveena BJ, Reddy $G$. Use of inexpensive nitrogen sources and starch for $L(+)$ lactic acid production in anaerobic submerged fermentation. Bioresour Technol. 2007;98(3):498-503.

22. Zhou JJ, Shen JT, Jiang LL, Sun YQ, Mu Y, Xiu ZL. Selection and characterization of an anaerobic microbial consortium with high adaptation to crude glycerol for 1,3-propanediol production. Appl Microbiol Biotechnol. 2017;101(15):5985-96.

23. Zhang QH, Tian M, Tang L, Li HX, Li WC, Zhang JH, Zhang HJ, Mao ZG. Exploration of the key microbes involved in the cellulolytic activity of a microbial consortium by serial dilution. Bioresour Technol. 2013;132:395-400.

24. Hu J, Lin Y, Zhang Z, Xiang T, Mei Y, Zhao S, Liang Y, Peng N. High-titer lactic acid production by Lactobacillus pentosus FL0421 from corn stover using fed-batch simultaneous saccharification and fermentation. Bioresour Technol. 2016;214:74-80.

25. Malmierca S, Diez-Antolinez R, Paniagua Al, Martin M. Technoeconomic study of biobutanol AB production. 1. biomass pretreatment and hydrolysis. Ind Eng Chem Res. 2017;56(6):1518-24.

\section{Figures}



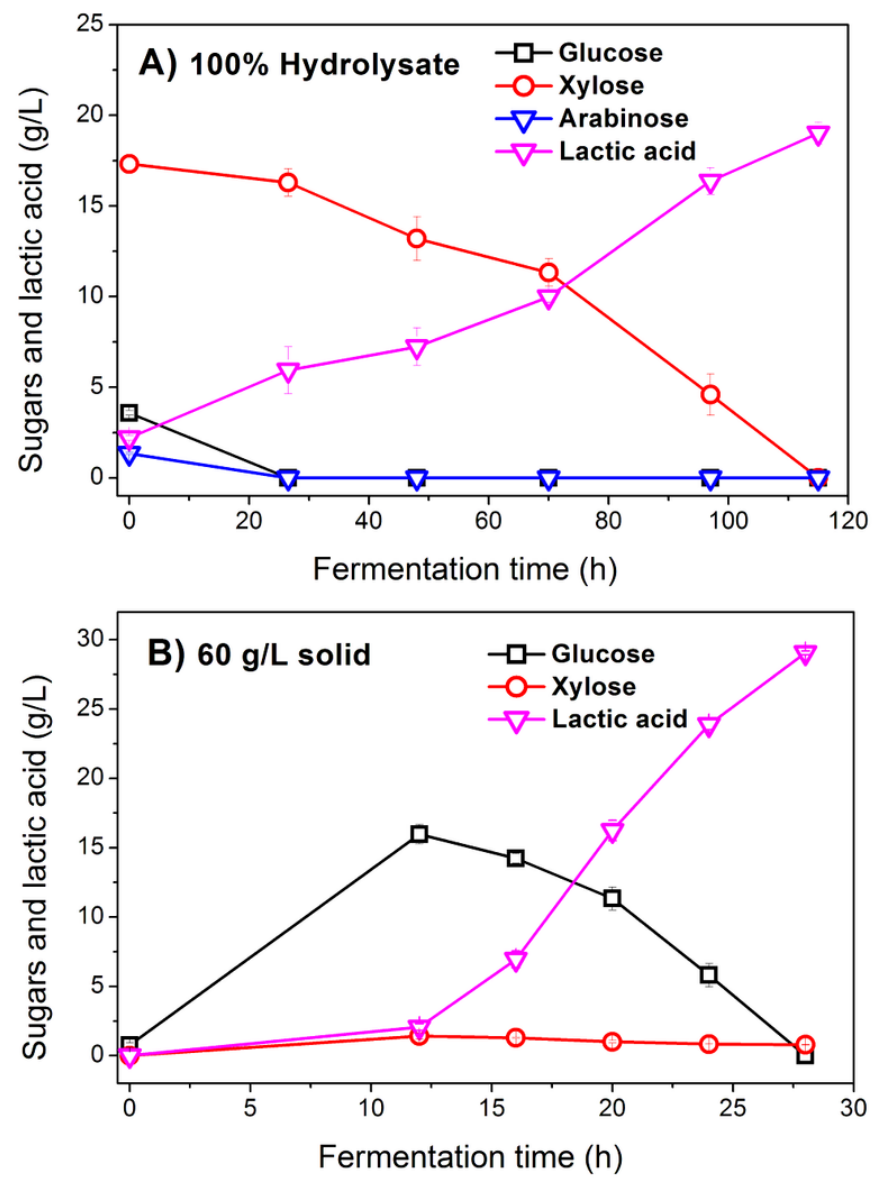

Figure 1

Lactic acid production by consortium DUT50 from the hydrolysate liquor and solid fraction of pre-CS. (A) $100 \%$ (v/v) hydrolysate liquor; (B) $60 \mathrm{~g} / \mathrm{L}$ solid fraction. Conditions: $1 \mathrm{~L}$ bioreactor containing $500 \mathrm{~mL}$ CSLP medium, 10\% (w/v) of dry biomass loading, $25 \mathrm{FPU} / \mathrm{g}-\mathrm{CS}$ cellulase, $20 \mathrm{~g} / \mathrm{L}$ CSLP, $12 \mathrm{~h}$ prehydrolysis time, 50oC, $\mathrm{pH} 5.5$. 

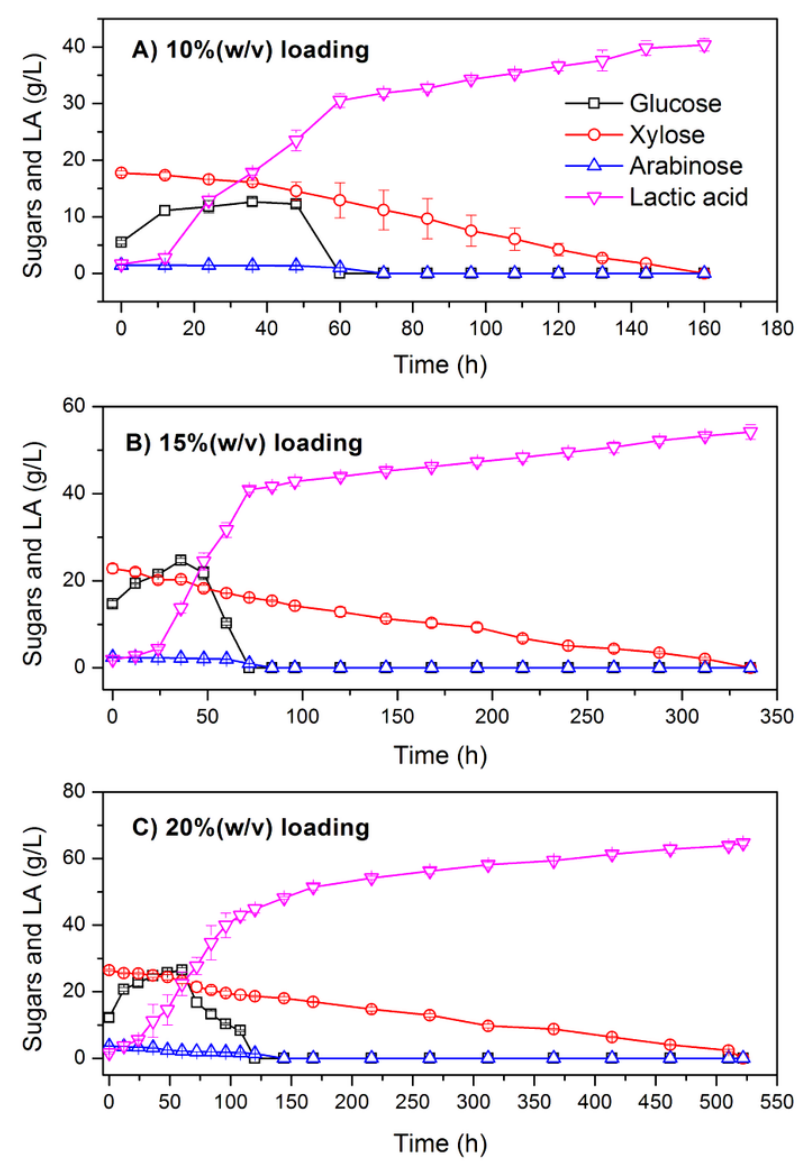

\section{Figure 2}

LA production via the SSCF process from non-detoxified acid-pretreated corn stover by microbial consortium DUT50. (A) 10\% (w/v) dry biomass loading, 7.34 $\mathrm{g} / \mathrm{L}$ total inhibitors; (B) 15\% (w/v) dry biomass loading, $9.46 \mathrm{~g} / \mathrm{L}$ total inhibitors; (C) 20\% (w/v) dry biomass loading, $10.90 \mathrm{~g} / \mathrm{L}$ total inhibitors. Conditions: $1 \mathrm{~L}$ bioreactor containing $500 \mathrm{~mL}$ CSLP medium, $35 \mathrm{FPU} / \mathrm{g}$-CS cellulase, $20 \mathrm{~g} / \mathrm{L}$ CSLP, 12 h pre-hydrolysis time, 50oC, pH 5.5 .

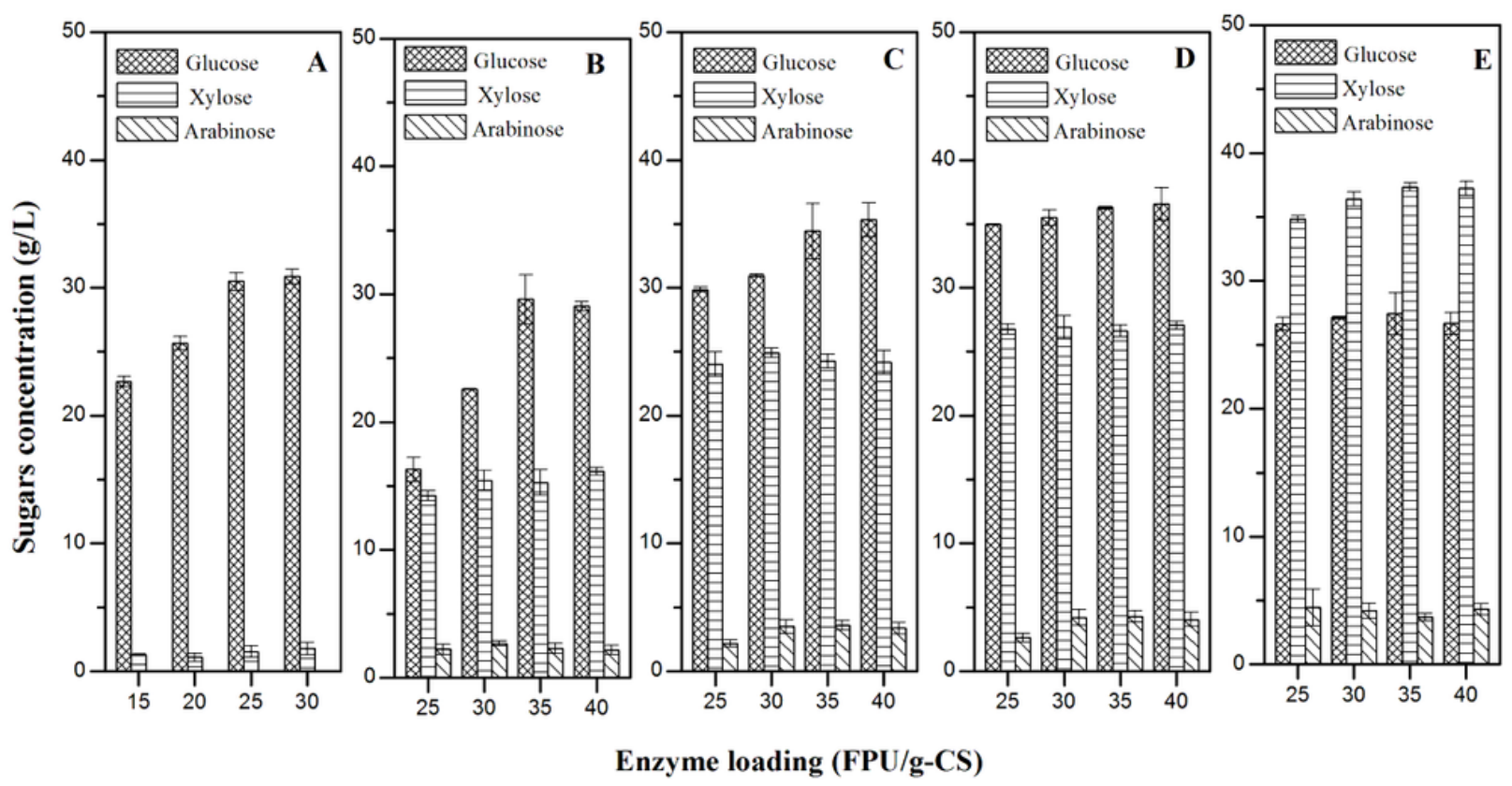

Page 10/12 
Figure 3

The effect of inhibitors and enzyme loading on the hydrolysis of detoxified and non-detoxified pre-CS. (A) $6 \%$ (w/v) solid fraction of pre-CS, $0 \mathrm{~g} / \mathrm{L}$ total inhibitors; (B) 10\% (w/v) dry biomass loading, $7.34 \mathrm{~g} / \mathrm{L}$ total inhibitors; (C) 15\% (w/v) dry biomass loading, $9.46 \mathrm{~g} / \mathrm{L}$ total inhibitors; (D) 20\% (w/v) dry biomass loading, $10.90 \mathrm{~g} / \mathrm{L}$ total inhibitors; (E) 25\% (w/v) dry biomass loading, $12.13 \mathrm{~g} / \mathrm{L}$ total inhibitors. Conditions: $1 \mathrm{~L}$ bioreactor containing $500 \mathrm{~mL} C S L P$ medium, 25-40 FPU/g-CS cellulase, $20 \mathrm{~g} / \mathrm{L}$ CSLP, $50 \mathrm{oC}, \mathrm{pH} 5.5$.

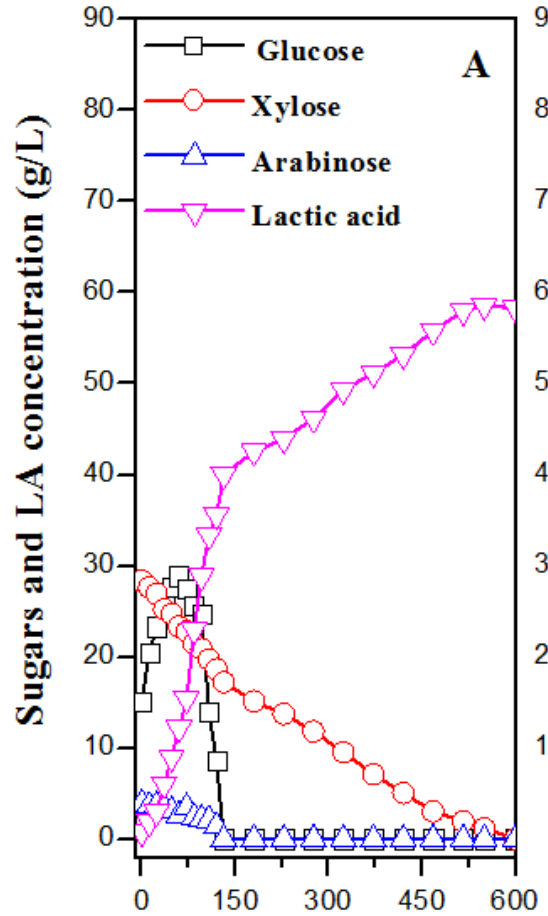

Time (h)

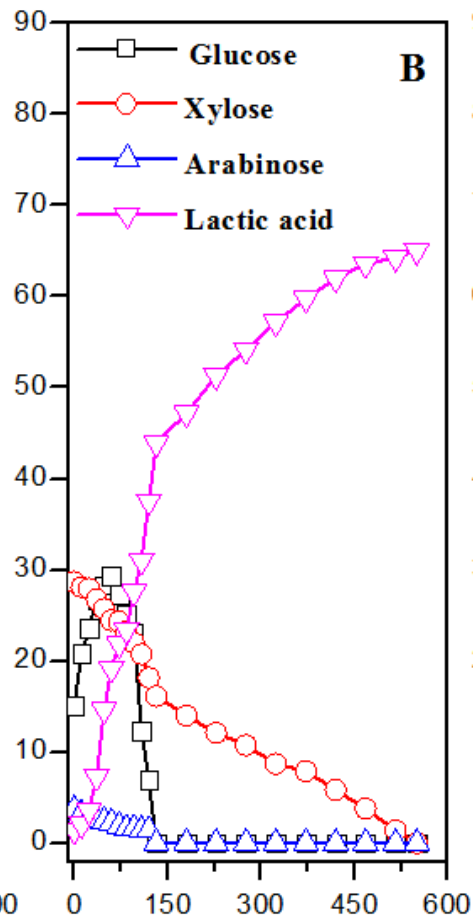

Time (h)

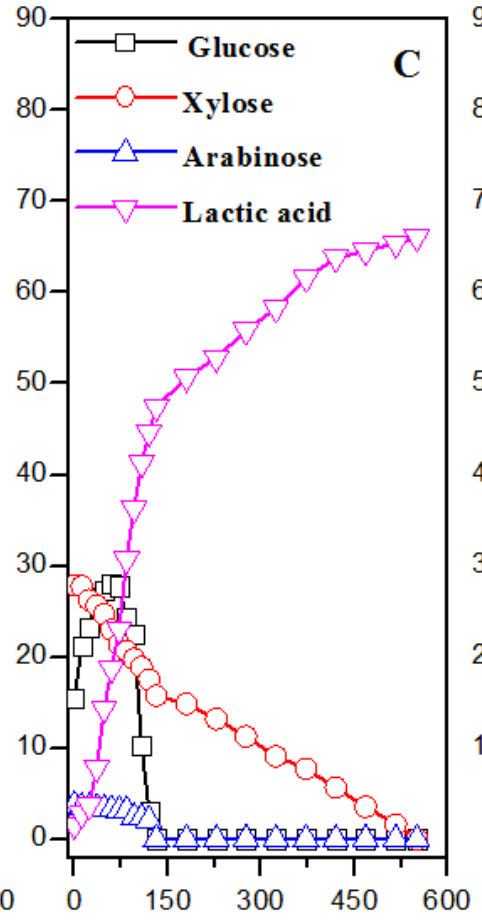

Time (h)

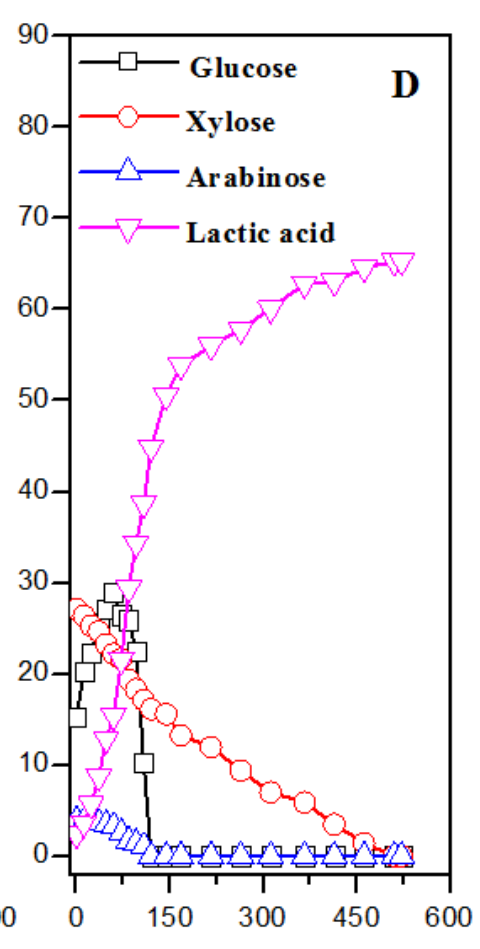

Time (h)

Figure 4

The effect of CSLP concentration on LA production via SSCF process from non-detoxified pre-CS. (A) $10 \mathrm{~g} / \mathrm{L} \mathrm{CSLP,} \mathrm{(B)} 15 \mathrm{~g} / \mathrm{L}$ CSLP, (C) $20 \mathrm{~g} / \mathrm{L}$ CSLP, (D) 25 g/L CSLP. Conditions: $1 \mathrm{~L}$ bioreactor containing $500 \mathrm{~mL}$ CSLP medium, 20\% (w/v) dry CS loading including $10.90 \mathrm{~g} / \mathrm{L}$ total inhibitors, $35 \mathrm{FPU} / \mathrm{g}$-CS cellulase, $12 \mathrm{~h}$ pre-hydrolysis time, $50 \mathrm{oC}, \mathrm{pH} 5.5$.

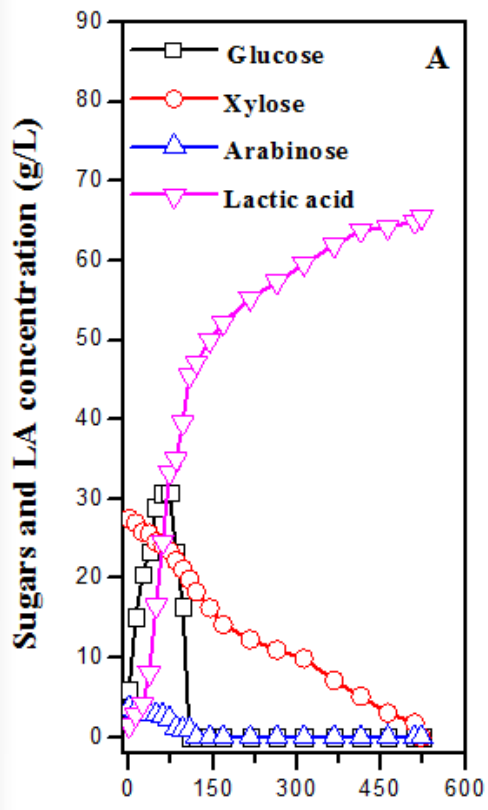

Time (h)

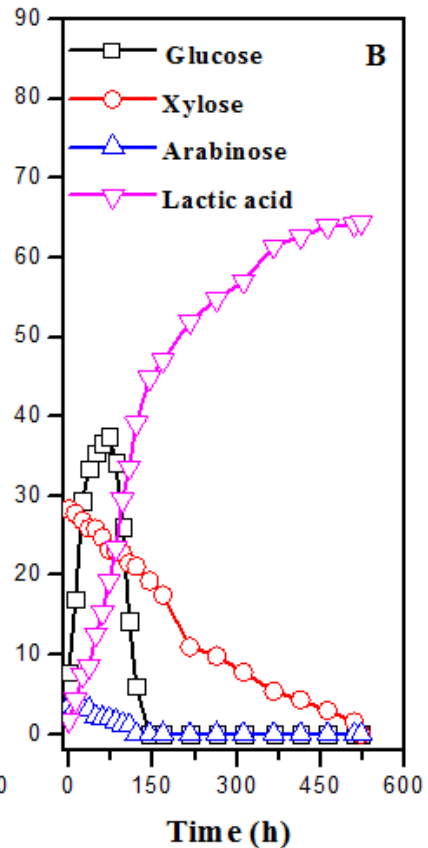

Time (h)
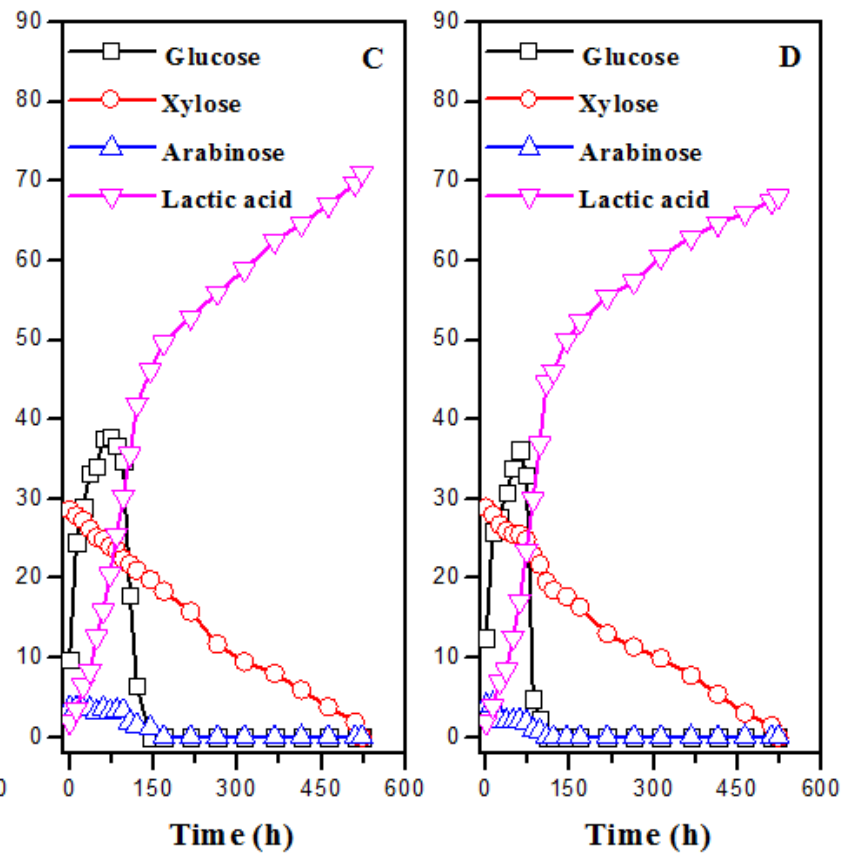

Figure 5 
The effect of pre-hydrolysis time on LA production via the SSCF process from non-detoxified pre-CS. (A) $0 \mathrm{~h}$, (B) $2 \mathrm{~h}$, (C) $4 \mathrm{~h}$, (D) $6 \mathrm{~h}$. Conditions: $1 \mathrm{~L}$ bioreactor containing $500 \mathrm{~mL}$ CSLP medium, 20\% (w/v) dry CS loading including $10.90 \mathrm{~g} / \mathrm{L}$ total inhibitors, $35 \mathrm{FPU} / \mathrm{g}-\mathrm{CS}$ cellulase, $20 \mathrm{~g} / \mathrm{L} \mathrm{CSLP,} 50 \mathrm{oC}, \mathrm{pH} 5.5$.
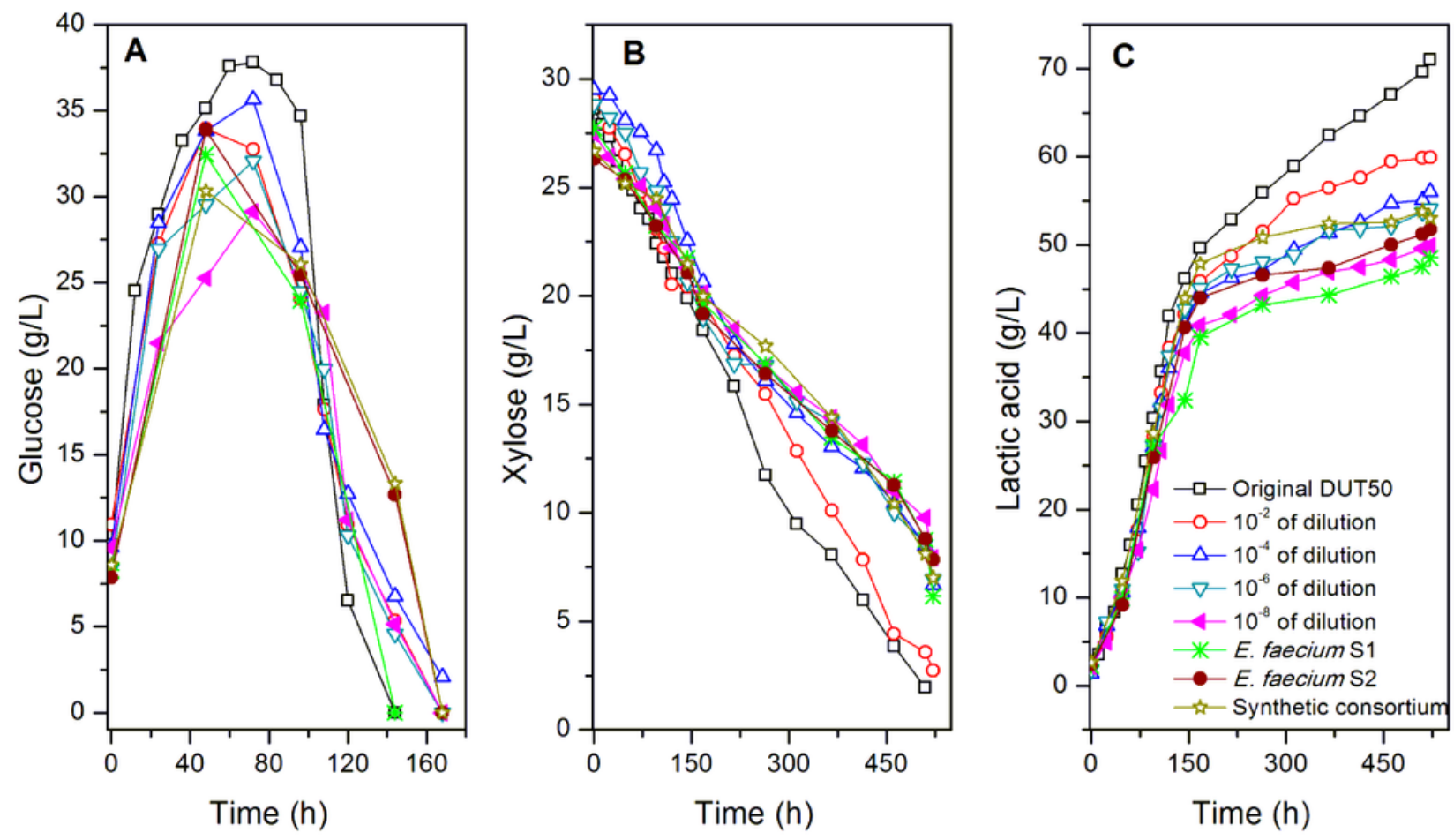

\section{Figure 6}

Performances of diluted consortia, E. faecium, and synthetic consortium for LA production from non-detoxified pre-CS. Conditions: $1 \mathrm{~L}$ bioreactor containing $500 \mathrm{~mL}$ CSLP medium, $20 \%(\mathrm{w} / \mathrm{v})$ dry CS loading including $10.90 \mathrm{~g} / \mathrm{L}$ total inhibitors, $35 \mathrm{FPU} / \mathrm{g}$-CS cellulase, $20 \mathrm{~g} / \mathrm{L} \mathrm{CSLP,} 4 \mathrm{~h}$ pre-hydrolysis time, 50 oC , pH 5.5 . 